\title{
An hypothesis about the training of intelligence
}

\author{
Jonathan Baron, Univeristy of Pennsylvania
}

[Citation: Baron, J. (1987). An hypothesis about the training of intelligence. In D. N. Perkins, J. Lochhead, \& J. Bishop (Eds.), Thinking: the second international conference. Hillsdale, NJ: Erlbaum.]

I wish to offer a "best guess" hypothesis, consistent with the evidence I know of, which, if it is correct, implies that those of us who want to teach people to be more intelligent will have to be aware of some limitations on what we can do. I conceive of teaching intelligence as training of certain abilities in substantial generality, that is, so that they are broadly useful. ${ }^{1}$

In brief, some abilities can be trained this way and others cannot. Skills, narrowly conceived, cannot be trained in general. Methods or strategies can be trained in general, but there are few at best that are powerful enough to count as parts of intelligence. The abilities that can be trained most usefully may be called styles. I have in mind things like thoroughness in searching for evidence, willingness to consider alternative possibilities, and fairness in the way one goes about searching for evidence and using it. To some extent, these styles may be taught as habits, the way one teaches good manners. But I think a more productive way to teach them is by instilling appropriate goals and beliefs. Just as we may teach good manners by instilling a concern for others, we may teach good thinking by instilling a concern for the truth and a belief that it is possible to get to the bottom of things through our own efforts. In essence, the teaching of intelligence, like the teaching of moral behavior, involves the enforcement of certain standards of conduct.

The question of whether any aspects of intelligence can be taught is not one we can answer definitively now. It is like the question, "Can diet prevent heart disease?" What we want is a best guess for practical purposes, not a conclusive scientific demonstration - although that would always be nice. Thus, it is inappropriate to argue that the burden of proof is on one side or the other. The practical issue before us involves the probable costs and benefits of various proposals, not scientific certainty.

There are a few facts that make me think that the teaching of intelligence is possible. First, there is the cross-cultural evidence about the effects of schooling. In many countries, it is unfortunately still possible to do experiments on children who seem to differ only in that some of them go to school and others do not. In every study I know in which this has been done, (e.g., Stevenson et al., 1978) schooling has been found to have substantial beneficial effects on the performance of problem-solving and memory tasks. The tasks in question

\footnotetext{
${ }^{1}$ Without this stipulation, we would not be training intelligence, but rather some specific piece of knowledge or skill. I would further stipulate that there ought to be essentially no limit on the domains where a component might prove useful. This stipulation follows from my view (Baron, 1985a) that intelligence should be defined so as to help people achieve their rational goals whatever these goals might be.
} 
are not directly taught in school, so it appears that the children have learned something general. ${ }^{2}$

Another type of study looks at the overall effect of extended training programs, particularly those for preschool children. The best guess about why these programs often succeeded in improving school achievement is that they instilled the goals and beliefs associated with good school work. The preschool programs in question had only short lasting effects, at best, on IQ scores (Lazar et al., 1982; Scarr \& Carter-Saltzman, 1982; Zigler \& Seitz, 1982). It should be noted, however, that these programs were not generally designed to increase intelligence as such, and certainly made no attempt to teach good thinking. Rather, they seem to resemble the programs designed to improve achievement motivation in older children, which have also been successful (e.g., Kolb, 1965). I know of only one of these studies, that of Blank (1973), that has directly set about to teach good thinking in the sense I think would work, and to my knowledge it has not been followed up. What the studies we have do indicate, however, is that character can be changed through explicit interventions.

Aside from these special interventions, there is a great deal of evidence (e.g., Jencks et al., 1972; Scarr \& Carter-Saltzman, 1982) that children's family background has a large influence on their IQ scores, beyond the influence of heredity. Family background has an even larger influence on school achievement and on worldly success. I have argued (Baron, 1985a) that IQ tests underrepresent the personality components of intelligence. Hence, the effect of family background on school achievement suggests that these components are indeed malleable to a considerable degree and that the home conditions of many children could stand improvement.

Another source of evidence for the trainability of good thinking comes from observations of the errors that people make in problem solving tasks. Many workers have noticed that mistakes in problem solving seem not to be the result of forgetting or lack of speed but rather the result of a kind of unreasonableness in the way the subject approaches the problem (Selz, 1935; Bloom and Broder, 1950; Whimbey and Whimbey, 1975). Errors are caused by sticking to the wrong approach even when it is obviously leading nowhere, by guessing without checking, and by giving an answer that could easily be seen not to meet the requirements of the task. For example, many workers have noticed that errors in analogy problems are often associates of the third term, with no attention given to whether the relation between terms one and two is preserved in terms three and four. In my own observations of people solving problems in Raven's Progressive Matrices, a test often given without a time limit, I have seen subjects frequently guess about the answer without being sure and without bothering to check. Further, several studies (e.g., Baron, Badgio, \& Gaskins, 1985; Galotti, Baron, \& Sabini, in press) have now shown that successful problem solvers often spend more time per problem than less successful ones. It seems likely that such stylistic factors as the amount of time one spends is under control, and therefore

\footnotetext{
${ }^{2}$ It might be argued that no further improvement in general abilities is possible once a child attends school. There is no reason to think this is true, and some reason - specifically, the other evidence I shall cite - to think it is false.
} 
teachable. (Further evidence on this point will be presented below.) ${ }^{3}$

Now for my long promised hypothesis about the training of intelligence. It is that intelligence cannot be trained at all by training skills - in a narrow sense of the term - but it can be trained by training styles and their associated beliefs and goals.

First, consider skills. In the narrow sense of the term "skill," the way to improve a skill is to practice it. As a result of practice, skills increase in speed and accuracy. For this to happen, it is not necessary for the subject to do anything in a different way; that would be counted as a change in method or strategy. The evidence is that skills can be improved with practice; indeed, they can become essentially automatic. However, when such improvement occurs, it does not transfer to stimuli in a different category. This was the conclusion of Thorndike and Woodworth (1901) and it is fully consistent with more recent data as well (see Woodworth and Scholsberg, 1954, ch. 24, and Baron, 1985b, for reviews). To take a dramatic recent example, Eriksson, Chase, and Faloon (1980) gave a normal undergraduate extensive practice at memorizing strings of numbers. The subject's span increased from about 7 digits to about 79 . The improvement was apparently the result of changes in method, but there was also a clear opportunity to practice the task itself. Despite this opportunity, the subject's span for letters was unchanged; it remained about 6 . Consistent with earlier conclusions, one does not build one's memory ability in general by practice at specific kinds of memorization.

This conclusion about skills, if true, has a broader implication for the teaching of intelligence. In some writing about teaching - and perhaps in some teaching - it is claimed that the way to teach something is to set up a goal for the student and provide practice at achieving that goal, with corrective feedback. Thus, if we want to teach creativity, we give exercises in creativity; if we want to teach people to understand the main point of a text, we ask them to read texts; if we want to improve the ability to discriminate visual forms, we provide practice at it; and if we want to teach intelligence, we give children practice at test items like those on the IQ test. Such training may sometimes work, for the students may discover new methods that help them in the tasks where they are trained and even in a few related tasks. The students may also change their style, for example, they may learn to become more cautious; and they may become more motivated, more concerned about achieving certain kinds of goals. But our best guess is that they are not improving because of increases in skills. If there appears to be such improvement, it is limited to the tasks on which the training is given.

It has been suggested that much of intelligence consists of strategies or meth-

\footnotetext{
${ }^{3}$ It may be argued that variation in style is small compared to variation in more basic properties of performance such as mental speed. However, when speed is important in life, there is often an opportunity to improve one's speed at a specific task through practice, and practice effects may be large compared to individual variation. In many of the important things in life, such as decision making of the sort that extends over days or weeks, speed is not really an issue at all, but styles such as one's openness to alternatives and to evidence may well be important.
} 
ods, and these can be taught (Flavell, 1970; Brown, 1974; Baron, 1978). This discussion was inspired by demonstrations that the memory deficiencies of retardates (in particular) could be partially remediated by teaching the subjects strategies for memorizing. Recently, a number of studies have shown that transfer to new situations will occur when pains are taken to provide the training in a generalizable, transferrable way (e.g., Brown, Campione, and Barclay, 1979). Although this work seems promising, I have a couple of questions about it. First, although the teach of strategies may be worthwhile, a strategy seems more like a specific piece of knowledge rather than a component of intelligence. Few if any strategies are sufficiently general to meet the criterion of generality I proposed earlier, and those that are seem very much like styles (Baron, 1985b). Second, it seems likely that many of these successful training studies actually change the subjects' styles as well as their specific strategies. In most training studies involving memory strategies, the trained strategy takes longer to use than what the subject was doing before, and extra time is required in transfer as well. Training children to be less impulsive and more self critical might suffice to produce the same results even in the absence of strategy training. In this case, I would argue that there has been a true change in intelligence, for such style changes are substantially general in the sense I described.

A number of training studies have been directed more explicitly at the kind of styles I have alluded to. In an important paper by Otto Selz (1935) a few of these studies are reviewed. One of the most revealing of these studies was a thesis done by Jakob Andrae under Selz's supervision. In this study, an experimental and control group of students, age 11-13, were given an intelligence test consisting of completion tests (stories with words left out), word ordering, verbal analogies, and number-series completions. The experimental groups was given training on only the completion test for one hour on two successive days. The training was designed to make students take into account the requirements of the task, checking each possible answer to see if these requirements were met. Subjects were taught both to explain why answers did not meet the requirements and to justify answers when they seemed to fit. The training was done in the form of what seemed to be a lively competitive exercise in which students were called upon to defend their answers at the blackboard while other students in the group chimed in with criticisms and explanations. After the training, a second intelligence test was given. The experimental group showed substantial improvement not only on the completion test but also on all the others, to roughly the same extent. For example, on one of the completion tests, the experimentals improved from $60 \%$ to $78 \%$ correct while the controls improved from $60 \%$ to $63 \%$, and on the analogy test, the experimentals went from $28 \%$ to $69 \%$ while the controls went from $33 \%$ to $41 \%$. Of great interest, I think, is the finding that the experimental group was more than twice as likely than the control group to scratch out an answer and correct it in the posttest (244 times vs. 103), although the experimentals were less likely to do this in the pretest (22 times vs. 41). Again, this finding held to a roughly equal extent over all tasks. Although these results were from a short term study with an immediate posttest, there is no reason to think that they would change qualitatively with 
more extensive training and a more delayed posttest. Selz's explanation of these effects is very much in the spirit of my own theorizing, although he uses the term Verhaltungsweisen - roughly, modes of conduct - where I use the term styles.

In a more recent attempt, Irene Gaskins and I conducted an eight month training study in her school for reading-disabled children, the Benchmark School (Baron et al., 1985). The teachers in the school (including Gaskins) identified three styles that they felt were holding many children back from academic success, even when their initial reading problems had been largely corrected. We called these styles impulsiveness, rigidity, and nonpersistence. Impulsiveness consists of failing to think sufficiently on an individual problem or when answering a question. Rigidity consisted of an unwillingness to consider alternatives to one's initial hypothesis about how something should be done or about the truth of some issue. Nonpersistence was the failure to complete extended activities, such as seat-work assignments; it can be taken as a sign of lack of motivation. Our training program tried to overcome these biases by enphasizing three slogans: "Take time to think," "Consider alternatives," and "Keep at it." The value of these new styles was explained in terms of hypothetical examples; exercises were done; children were given feedback about their actual classroom behavior.

The program was a success according to teacher ratings of the styles we tried to train; the experimental group improved considerably and the control group hardly at all. The training also affected ratings of academic performance given by teachers of children who had graduated Benchmark and gone to other schools. In addition, children did slow down and take more time to think in a few different laboratory measures using tasks other than those used in training. Those children who had been rated as particularly impulsive also improved in their overall accuracy on these tasks. Tasks that showed these effects included an test of arithmetic word problems and a test of syllogisms. Since syllogisms have been used on IQ tests, we have some reason to think that training of this sort would help performance on IQ tests, at least those on which speed is not an important element in scoring. But this is not an important point for my argument, for I suspect that IQ tests are in general relatively insensitive to the stylistic components of intelligence. One informal observation of our study was that it was quite easy to teach children to go through the motions of spending more time on the task, checking their work, and so on, as long as the teacher was standing over them with the proverbial whip. What was more difficult was to instill the goals and beliefs that would insure that they would maintain their new styles, or Verhaltungsweisen, outside of the training sessions.

It is my hunch that the inculcation of these goals and beliefs is the most important aspect of any effort to teach intelligent thinking. Good thinkers, I think, are those who believe that intuition is often not the last word, that a considered judgment or answer is more likely to be correct than an unconsidered one, and that individuals can often figure things out for themselves. Good thinkers also have the goals of wanting to be correct or to make the best decision, rather than the goal of having been right all along, and the goal of being prudent in the service of long-term interests of themselves and others rather than the 
pursuit of immediate satisfactions. I would thus argue that the teaching of intelligence is part of the teaching of character. In teaching people to think well, we are trying to maintain and extend certain intellectual standards, much in the way we maintain moral standards in teaching other kinds of conduct.

\section{References}

Baron, J. (1978) Intelligence and general strategies. In G. Underwood (Ed.) Strategies in information processing. New York: Academic Press, 1978, pp. 403-450.

Baron, J. (1985a) Rationality and intelligence. Cambridge: Cambridge University Press.

Baron, J. (1985b) What kinds of intelligence components are fundamental? In S.F. Chipman, J.W. Segal, \& R. Glaser (Eds.) Thinking and learning skills. Vol. 2: Research and open questions. Hillsdale, NJ: Erlbaum, pp. 365-390.

Baron, J., Badgio, P., \& Gaskins, I.W. (1985) Cognitive style and its improvement: A normative approach. In R.J. Sternberg (Ed.), Advances in the psychology of human intelligence, Vol. 3. Hillsdale, NJ: Erlbaum.

Blank, M. (1973) Teaching learning in the preschool. Columbus, Ohio: Merrill.

Bloom, B., \& Broder, L., (1950) Problem-solving processes of college students. Chicago: University of Chicago Press.

Brown, A.L. (1974) The role of strategic behavior in retardate memory. In N.R. Ellis (Ed.), International review of research in mental retardation, Vol. $\%$. New York: Academic Press.

Brown, A.L., Campione, J.C., \& Barclay, C.R. (1979) Training self-checking routines for estimating test readiness: generalization from list learning to prose recall. Child Development, 50, 501-512.

Ericsson, K.A., Chase, W.G., \& Faloon, S. (1980) Acquisition of a memory skill. Science, 208, 1181-1182.

Flavell, J.H. (1970) Developmental studies of mediated memory. In H.W. Reese \& L. P. Lipset (Eds.), Advances in child development and behavior, Vol. 5. New York: Academic Press.

Galotti, K.M., Baron, J., \& Sabini, J. (in press) Individual differences in syllogistic reasoning: deduction rules or mental models. Journal of Experimental Psychology: General.

Jencks, C., Smith, J., Ackland, H., Bane, M.J., Cohen, D., Gintis, H., Heyns, P., \& Michelson, S. (1972) Inequality: a reassessment of the effect of familt and schooling in America. New York: Basic Books.

Kolb, D.A. (1965) Achievement motivation training for underachieving highschool boys. Journal of Personality and Social Psychology, 2, 783-792.

Lazar, I., Darlington, R., et al. (1982) Lasting effects of early education: a report from the consortium for longitudinal studies. Monographs of the Society for Research in Child Development, 47, Serial No. 195.

Scarr, S., \& Carter-Saltzman, L. (1982) Genetics and intelligence. In R.J. Sternberg (Ed.) Handbook of human intelligence. New York: Cambridge University 
Press.

Selz, O. (1935) Versuche zur hebung des intelligenzniveaus: ein Beitrag zur Theorie der Intelligenz und ihrer erziehlichen Beeinflussung. Zeitschrift fr Psychologie, 134, 236-301.

Stevenson, H.W., Parker, T., Wilkinson, A., Bonnevaux, B., \& Gonzalez, M. (1978) Schooling, environment, and cognitive development: a cross cultural study. Monographs of the Society for Research in Child Development, 43, Serial No. 175.

Thorndike, R.L., \& Woodworth, R.R. (1901) The influence of improvement in one mental function upon the efficiency of other functions. Psychological Review, 8, 247-261.

Whimbey, A., \& Whimbey, L.S. (1975) Intelligence can be taught. New York: Dutton, 1975.

Woodworth, R.S., \& Schlosberg, H. (1954) Experimental Psychology. New York: Holt.

Zigler, E. \& Seitz, V. (1982) Social policy and intelligence. In R.J. Sternberg (Ed.) Handbook of human intelligence. New York: Cambridge University Press. 